\title{
PENGARUH FREKUENSI PEMUTARAN DAN POSISI TELUR PADA KEBERHASILAN PENETASAN TELUR AYAM KAMPUNG (Gallus gallus Domesticus)
}

\author{
Jecqueline C. M. Eoudia, Lucia J. Lambey*, Josephine L. P. Saerang, Fredy J. Nangoy
}

Fakultas Peternakan Universitas Sam Ratulangi Manado, 95115.

\begin{abstract}
ABSTRAK
Penelitian ini bertujuan untuk mengetahui pengaruh frekuensi pemutaran dan posisi telur terhadap keberhasilan penetasan telur ayam kampung dengan menggunakan 162 butir telur ayam kampung yang dimasukkan dalam mesin tetas kapasitas 300 butir dan telah dilaksanakan selama 24 hari. Rancangan percobaan menggunakan rancangan acak lengkap faktorial yang terdiri atas 9 perlakuan dan 3 ulangan. Faktor perlakuan terdiri dari frekuensi pemutaran 2 kali, 3 kali, 4 kali perhari dan posisi telur $30^{\circ}$, $60^{\circ}, 90^{\circ}$. Hasil analisis keragaman menunjukan bahwa pengaruh frekuensi pemutaran tidak menunjukan pengaruh yang nyata $(\mathrm{P}>0.05)$ terhadap daya tetas. Posisi telur berpengaruh nyata $(\mathrm{P}<0.5)$ terhadap daya tetas. Tidak terdapat interaksi antara frekuensi pemutaran dan posisi telur terhadap daya tetas dan mortalitas. Kesimpulan dari penelitian ini yaitu frekuensi pemutaran 2 kali perhari dengan posisi kemiringan telur $30^{\circ}$ menghasilkan daya tetas yang cukup baik dan rendahnya tingkat mortalitas.
\end{abstract}

Kata kunci : Ayam kampung, frekuensi pemutaran dan posisi telur, daya tetas.

*Korespondensi (corresponding author):

Email: lucialambey@yahoo.com
ABSTRACT

\begin{abstract}
EFFECT OF TURNING FREQUENCY AND EGG POSITION ON HATCHABILITY OF CHICKEN EGGS (Gallus gallus Domesticus). This study aimed to determine effect of turning frequency and egg position on the hatching ability of chicken eggs. Study was conducted using 162 eggs of local hens inserted into hatching machine with capacity of 300 eggs and implemented for 24 days. The experimental design of the completely factorial randomized design was applied consisting of 9 treatments and 3 replications. The two treatment factors were turning frequency consisted of 2 times a day, 3 times a day, 4 times a day, and egg position of $30^{\circ}, 60^{\circ}$, and $90^{\circ}$. The results of the analysis show that the effect of the turning frequency did not show a significant effect $(\mathrm{P}>0.05)$ on hatchability. However, egg position had a significant effect $(\mathrm{P}<0.5)$ on hatchability. There was no interaction between turning frequency and egg position againt hatchability and mortality. The conclusion of this research was the turning frequency of 2 times a day with egg slope position of $30^{\circ}$ produced high hatchability and low level of mortality.
\end{abstract}

Keywords : Egg turning frequency and position, hatchability, local hen.

Ayam lokal atau ayam kampung juga dikenal dengan sebutan ayam buras (bukan ras), atau ayam sayur merupakan ayam asli Indonesia yang kehidupannya sudah lekat dengan masyarakat. Penampilan ayam lokal sangat beragam, begitu pula sifat genetikanya. Penyebarannya sangat luas dan dapat dijumpai di daerah pedesaan maupun daerah perkotaan. 
Potensinya cukup baik untuk dikembangkan baik untuk meningkatkan gizi masyarakat

Menurut King'Ori (2011) Produksi
unggas semakin populer di negara-negara berkembang karena perannya dalam menjembatani segmen masyarakat miskin sumber daya dan juga cocok dalam sistem peternakan yang biasa dipraktikkan. Untuk menunjang perkembangan peternakan ayam kampung, selain pakan dan tatalaksana (manajemen), penyediaan bibit yang baik merupakan hal penting untuk mendapatkan produksi yang maksimal. Semakin meningkatnya perkembangan usaha peternakan maka membutuhkan peningkatan usaha pembibitan melalui penetasan, oleh sebab itu pengetahuan dan keterampilan tentang hal pengelolaan penetasan telur perlu ditingkatkan dan ditangani dengan serius (Rasyaf, 1995). Pemutaran telur yang dilakukan peternak selama proses penetasan biasanya sebanyak dua kali/hari, yaitu pada pagi dan sore hari. Proses pemutaran telur yang tidak teratur dapat menyebabkan panas yang mengenai telur menjadi tidak merata sehingga embrio akan lengket pada kerabang dan akhirnya menyebabkan kematian embrio (Daulay et al., 2008).

Pada umumnya pemutaran telur dilakukan dua kali perhari dengan posisi telur miring (ujung tumpul berada diatas/letak kantung udara dan ujung tajam berada dibawah) namun belum pernah dilakukan penelitian dimana ketepatan posisi (derajat) kemiringan suatu telur. Berdasarkan hal tersebut maka dilakukan penelitian tentang maupun pendapatan keluarga (Syamsudin, 2016).

frekuensi pemutaran dan posisi telur terhadap fertilitas, daya tetas, dan bobot DOC ayam kampung.

\section{MATERI PENELITIAN}

\section{Bahan dan Alat}

Penelitian ini menggunakan 162 butir telur ayam kampung dengan berat $35-50 \mathrm{~g}$. Alat yang digunakan dalam penelitian ini adalah mesin tetas manual (sumber pemanas lampu dilengkapi thermostat, pembalikan manual dengan tangan). Kapasitas 300 butir telur ayam/unit mesin tetas. Suhu yang digunakan $38^{\circ} \mathrm{C}\left(100,4^{\circ} \mathrm{F}\right)$ dengan kelembaban $60 \%$. Peralatan lain sebagai pendukung adalah timbangan (untuk menimbang telur dan DOC), egg tray (tempat telur), termometer (untuk mengukur suhu mesin tetas), candler (alat teropong telur), dan nampan plastik.

\section{Metode Penelitian}

Adapun metode penelitian yang digunakan adalah Rancangan Acak Lengkap (RAL) Faktorial. Faktor pertama frekuensi pemutaran (F) yaitu: A1 (dua kali/hari), A2 (tiga kali/hari) dan A3 (empat kali/hari). Perlakuan frekuensi pemutaran telur dua kali/hari (A1): pukul 06.00, 18.00, tiga kali/hari (A2): pukul 06.00, 14.00, 22.00, dan empat kali/hari (A3): 06.00, 12.00, 18.00, 00.00. Pemutaran telur dimulai hari keempat setelah telur masuk mesin tetas sampai pada hari kedelapan belas. Faktor kedua adalah 
Tabel 1. Desain Penelitian

\begin{tabular}{|c|c|c|}
\hline Posisi Telur & Frekuensi Pemutaran (kali/hari) & Jumlah Telur \\
\hline \multirow{4}{*}{$30^{0}$} & $\mathrm{~A}=2$ kali sehari pada pukul $06.00,18.00$ WITA & 18 butir \\
\hline & $\mathrm{B}=3 \mathrm{kali}$ sehari pada pukul $06.00,14.00,22.00$ & 18 butir \\
\hline & $\mathrm{C}=4$ kali sehari pada pukul $06.00,12.00,18.00,00.00$ & 18 butir \\
\hline & WITA & \\
\hline \multirow{4}{*}{$60^{0}$} & $\mathrm{~A}=2$ kali sehari pada pukul $06.00,18.00 \mathrm{WITA}$ & 18 butir \\
\hline & $\mathrm{B}=3$ kali sehari pada pukul $06.00,14.00,22.00$ & 18 butir \\
\hline & $\mathrm{C}=4$ kali sehari pada pukul 06.00, 12.00, & 18 butir \\
\hline & $18.00,00.00$ WITA & \\
\hline \multirow{4}{*}{$90^{\circ}$} & $\mathrm{A}=2$ kali sehari pada pukul $06.00,18.00$ WITA & 18 butir \\
\hline & $\mathrm{B}=3 \mathrm{kali}$ sehari pada pukul $06.00,14.00,22.00$ & 18 butir \\
\hline & $\mathrm{C}=4$ kali sehari pada pukul $06.00,12.00,18.00,00.00$ & 18 butir \\
\hline & WITA & \\
\hline
\end{tabular}

Posisi Telur (B). Posisi telur $\mathrm{B}_{1}\left(30^{\circ}\right)$, Posisi telur $\mathrm{B}_{2}\left(60^{\circ}\right)$, dan posisi telur $\mathrm{B}_{3}\left(90^{\circ}\right)$.

Desain Penelitian

A1 = Pemutaran 2 kali perhari

A2 $=$ Pemutaran 3 kali perhari

A3 $=$ Pemutaran 4 kali perhari

$\mathrm{B} 1=$ Posisi $30^{\circ}$

$\mathrm{B} 2=$ Posisi $60^{\circ}$

$\mathrm{B} 3=$ Posisi $90^{\circ}$

Perlakuan frekuensi pemutaran telur dua

kali/hari (A1): pukul 06.00, 18.00, tiga

kali/hari (A2): pukul 06.00, 14.00, 22.00, dan empat kali/hari (A3): 06.00, 12.00, 18.00, 00.00. Pemutaran telur dimulai hari keempat setelah telur masuk mesin tetas sampai pada hari kedelapan belas. Faktor kedua adalah Posisi Telur (B). Posisi telur $\mathrm{B}_{1}\left(30^{\circ}\right)$, Posisi telur $\mathrm{B}_{2}\left(60^{\circ}\right)$, dan posisi telur $\mathrm{B}_{3}\left(90^{\circ}\right)$.

Desain Penelitian

A1 = Pemutaran 2 kali perhari

A2 $=$ Pemutaran 3 kali perhari

A3 = Pemutaran 4 kali perhari

$\mathrm{B} 1=$ Posisi $30^{\circ}$

$\mathrm{B} 2=$ Posisi $60^{\circ}$

B3 $=$ Posisi $90^{\circ}$ 


\section{HASIL DAN PEMBAHASAN}

\section{Pengaruh Frekuensi Pemutaran dan Posisi Telur terhadap Daya Tetas}

Menurut Onyinye (2018), Daya tetas merupakan sifat yang sangat penting secara ekonomi pada industri perunggasan, karena memiliki efek yang kuat pada produksi ayam. Hasil analisis data menunjukan persentase rata-rata daya tetas yang diperoleh berdasarkan frekuensi pemutaran dan posisi telur ayam kampung dapat dilihat pada Tabel 2 . Berdasarkan data diatas menunjukkan bahwa posisi telur $30^{\circ}$ dengan frekuensi pemutaran dua kali perhari cenderung menunjukkan daya tetas yang lebih tinggi yaitu 77,66\% dibandingkan dengan posisi telur $30^{\circ}$ dan frekuensi pemutaran tiga kali perhari yaitu $73,33 \%$ sedangkan posisi telur $30^{\circ}$ dan frekuensi pemutaran empat kali perhari mempunyai daya tetas rendah yaitu $70 \%$. Pada posisi telur $60^{\circ}$ dan frekuensi pemutaran tiga kali perhari cenderung mempunyai daya tetas yang lebih tinggi yaitu $70 \%$ dibandingkan dengan frekuensi pemutaran dua dan empat kali perhari. Posisi telur $90^{\circ}$ dan frekuensi pemutaran dua kali perhari menghasilkan daya tetas sebesar $51 \%$ lebih tinggi dibandingkan dengan daya tetas dari posisi telur $90^{\circ}$ dan frekuensi pemutaran tiga kali perhari yaitu $27,66 \%$ dan daya tetas pada posisi telur $90^{\circ}$ dan frekuensi pemutaran empat kali perhari yaitu $12,5 \%$.

Adanya perbedaan daya tetas pada frekuensi pembalikan telur yang berbeda diduga karena semakin banyaknya frekuensi pembalikan akan diikuti dengan semakin banyaknya pintu mesin tetas dibuka. Keadaan ini berpengaruh pada rendahnya suhu dan kelembapan pengeraman dalam mesin tetas. Menurut Tona, 2005 pentingnya pemutaran telur selama inkubasi dikarenakan efek dari frekuensi pemutaran terkait dengan tahap pengembangan embrio. Menurut French (2000) Daya tetas terendah diperoleh ketika telur diinkubasi pada suhu tinggi antara 7 hingga 12 hari dan 6 hingga 10 hari, yang menunjukkan bahwa embrio pada tahap perkembangan ini lebih cenderung menyerah pada suhu tinggi daripada pada usia lainnya. Peningkatan mortalitas embrio karena overheating terlihat pada minggu ke 3 dan 4

Tabel 2. Fekuensi Pemutaran dan Posisi Telur Terhadap Persentase Daya Tetas

\begin{tabular}{crccc}
\hline Posisi Telur & \multicolumn{3}{c}{ Frekuensi Pemutaran (\%) } & Rata-rata \\
\cline { 2 - 4 } & A1 & A2 & A3 & \\
\hline B1 & $77,66^{\mathrm{a}}$ & $73,33^{\mathrm{a}}$ & $70^{\mathrm{a}}$ & 73,66 \\
B2 & $58,33^{\mathrm{b}}$ & $70^{\mathrm{b}}$ & $63,33^{\mathrm{ab}}$ & 63,88 \\
B3 & $51^{\mathrm{b}}$ & $26,66^{\mathrm{c}}$ & $12,5^{\mathrm{c}}$ & 30,05 \\
\hline
\end{tabular}


dari inkubasi dan pada tahap pipping. Ini diamati bahkan ketika periode overheating terjadi pada minggu 1 dan 2 inkubasi. 5. Embrio malposisi dengan kepala mereka di ujung kecil telur terlihat pada insiden yang lebih tinggi ketika terlalu panas pada kuartal ke-2 atau ke-3 dari masa inkubasi.

Berdasarkan data hasil analisa statistik menunjukkan bahwa frekuensi pemutaran tidak menunjukkan pengaruh yang nyata $(\mathrm{P}>0,05)$ terhadap daya tetas. Hal ini kemungkinan disebabkan karena frekuensi pemutaran yang digunakan merupakan standar anjuran pemutaran telur. Posisi telur berpengaruh nyata $(\mathrm{P}<0,05)$ terhadap daya tetas. Hasil uji lanjut menggunakan Duncan's Multiple Range Test menunjukkan bahwa posisi $30^{\circ}$ dan $60^{\circ}$ tidak berbeda nyata sedangkan posisi kemiringan $90^{\circ}$ memberikan pengaruh yang nyata. Hal ini disebabkan karena posisi telur yang digunakan berbeda dalam sudut kemiringannya dan banyak mempengaruhi proses perkembangan embrio.

\section{Pengaruh Frekuensi Pemutaran dan Posisi Telur terhadap Mortalitas}

Menurut Robertson (1961) Penurunan angka kematian yang diamati dan karenanya peningkatan daya tetas pada tingkat pemutaran optimal sebagian besar disebabkan oleh kemungkinan perbaikan lingkungan fisiologis embrio. Berikut ini adalah persentase mortalitas terhadap masing-masing perlakuan dapat dilihat pada Tabel 3.

Berdasarkan data dari penelitian menunjukkan mortalitas tertinggi pada frekuensi pemutaran empat kali perhari yaitu $51,2 \%$ sedangkan pada pemutaran dua kali perhari mempunyai mortalitas terendah yaitu 29,25\%. Mortalitas pada posisi telur $90^{\circ}$ adalah $62,12 \%$ dan merupakan angka mortalitas tertinggi, sedangkan pada posisi telur $30^{\circ}$ cenderung mempunyai tingkat mortalitas terendah yaitu $21,66 \%$. Ini disebabkan karena pada posisi telur $90^{\circ}$ kantung udara tertekan oleh kuning telur yang naik secara otomatis keatas dan mempengaruhi pertumbuhan embrio dan dalam proses menetas.

Berdasarkan data hasil penelitian telah diuji secara statistik bahwa frekuensi pemutaran menunjukkan pengaruh yang nyata $(\mathrm{P}<0,05)$ terhadap mortalitas

Tabel 3. Frekuensi Pemutaran dan Posisi Tetas terhadap Persentase Mortalitas

\begin{tabular}{ccccc}
\hline & \multicolumn{3}{c}{ Frekuensi Pemutaran (\%) } & \multirow{2}{*}{ Rata-rata } \\
\cline { 2 - 4 } Posisi Telur & A1 & A2 & A3 & 21,66 \\
B1 & 8,33 & 26,66 & 30 & 35,92 \\
B2 & 41,66 & 30 & 36,11 & 62,12 \\
B3 & 37,77 & 61,11 & 87,5 & \\
\hline
\end{tabular}


Hal ini disebabkan oleh semakin banyaknya frekuensi pembalikan akan diikuti dengan semakin banyaknya pintu mesin tetas dibuka. Keadaan ini berpengaruh pada rendahnya suhu dan kelembapan pengeraman dalam mesin tetas. Menurut Nuryati (2009) bahwa kelembapan yang terlalu rendah dalam ruang mesin tetas selama periode penetasan menyebabkan laju penguapan air terlalu cepat sehingga embrio kekurangan air. Selanjutnya Wiharto (1988) meyatakan apabila suhu terlalu rendah umumnya menyebabkan kesulitan menetas dan bisa terjadi kematian embrio karena sumber pemanas yang dibutuhkan tidak mencukupi.

Posisi telur menunjukkan pengaruh nyata $(\mathrm{P}<0,05)$ terhadap mortalitas. Hal ini disebabkan karena posisi telur yang digunakan berbeda dalam sudut kemiringannya. Hasil uji lanjut menggunakan Duncan's Multiple Range Test menunjukkan bahwa frekuensi pemutaran dan posisi telur berbeda nyata.

\section{KESIMPULAN}

Dari hasil penelitian dan pembahasan dapat ditarik kesimpulan yaitu frekuensi pemutaran dua kali perhari dengan posisi kemiringan telur $30^{\circ}$ menghasilkan daya tetas yang cukup baik dan tingkat mortalitasnya rendah. Posisi telur yang tepat pada proses penetasan adalah posisi telur dengan kemiringan 30 .

\section{DAFTAR PUSTAKA}

Daulay, A.H., S. Aris, dan A. Salim. 2008. Pengaruh umur dan frekuensi pemutaran terhadap daya tetas dan mortalitas telur ayam Arab (Gallus turticus). USU. Sumatera Utara.

French NA. Effect of short periods of high incubation temperature on hatchability and incidence of embryo pathology of turkey eggs. Brit Poultry Sci. 2000;41(3):377-382.

King'Ori AM. Review of the factors that influence egg fertility and hatchability in poultry. Int J. Poult. Sci. 2011;10(6):483-492.

Nuryati, T. 2009. Sukses Menetaskan Telur. Penebar Swadaya . Jakarta.

Onyinye, C. O., M. A. Oguike. 2018 Hatchability of Fertile Eggs in Poultry Industry. J. of Agrc. and Sus., 12(1)

Rasyaf, M. 1995. Pengelolaan Peternakan Usaha Ayam Pedaging. Gramedia. Jakarta.

Robertson, I. (1961). The influence of turning on the hatchability of hens' eggs II. The effect of turning frequency on the pattern of mortality, the incidence of malpositions, malformations and dead embryos with no somatic abnormality. The J. of Agr. Sci., 57(1), 57-69.

Syamsudin, G. H., W.Tanwirah., E. Sujana. 2016. Fertilitas, Daya Tetas, dan Bobot Tetas Ayam Sentul Warso Unggul Gemilang Farm Bogor. Jurnal Peternakan. Universitas Padjajaran. Vol 5 (4).

Tona K, Onagbesan O, Bruggeman V, Mertens K, Decuypere E. Effects of turning duration during incubation on embryo growth, utilization of albumen, and stress regulation. J. Poult. Sci. 2005;84(2):315-320. 
Wiharto. 1988. Petunjuk Pembuatan Mesin Tetas. Lembaga Penerbit. Universitas Brawijaya. 